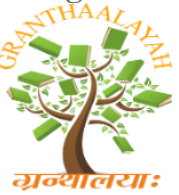

INTERNATIONAL JOURNAL OF RESEARCH GRANTHAALAYAH A knowledge Repository

Arts

\title{
TRICKS AND TECHNIQUE WITH OOPS (OIL ON PAPER SCHOOL)
}

\author{
Rajendra Bhatia *1 \\ ${ }^{* 1}$ MA (DNP), Director, Design IFAAA, Indore
}

\begin{abstract}
What if opaque colours can be used to create a play of transparency and translucency in the painting? Since the 14th century, artists have been playing around with various color pigments, binders and solvents to achieve transparency in opaque mineral pigments. These pigments when powdered and pulverized with drying oils such as linseed oil, provides an amazing platform for the artists to work on canvas or pre-treated paper, with an advantage of mixing of colours on the drawing surface and glaze after drying. The paper, briefly introduces artworks of artists made on non-treated and pre-treated paper using oil colours with respect to oil-paper compatibility and preservation of art work.

On the similar ground, an opaque blend of oil colours mixed with enamel or polyurethane with other solvents such as turpentine, kerosene and linseed oil, has been explored on art card paper to create some beautiful art works. Thus, demonstrating opacity, transparency and translucency within a single layer of applied paint which has been further explained by application of thin paint on black and white surfaces. In order to bring out such a play of light, various innovative techniques such as, scraping of color by a cloth, a palette knife or a wedge; creation of cells or bubbles and the sponge and rubber roller were used to get the desired effects. The unique effects, achieved through these techniques, have been displayed in various art works by the author, throughout the paper.

These techniques when clubbed together with the unconventional enamel mixed oil paints has been named by the author as OOPS (Oil on Paper School). OOPS results in the creation of some extraordinary pieces of art. They bring about the procedure of water colours for getting transparency and opaqueness and at the same time, they impart the property of oil colours (high hue of the pigments and an attractive glossy finish) onto the paper.

The paper concludes with a description and the author's perspective of one of his painting from the series 'Kargil White Again'-1999 (figure 1) with respect to the contextual and formal analysis. This painting is one of his finest pieces of work, where he explored the applications and future of OOPS in creation of some non-conventional art work.
\end{abstract}

Keywords: Tricks; Technique; Oops.

Cite This Article: Rajendra Bhatia. (2019). "TRICKS AND TECHNIQUE WITH OOPS (OIL ON PAPER SCHOOL)." International Journal of Research - Granthaalayah, 7(11SE), 52-69. https://doi.org/10.29121/granthaalayah.v7.i11.2019.982. 


\section{Introduction}

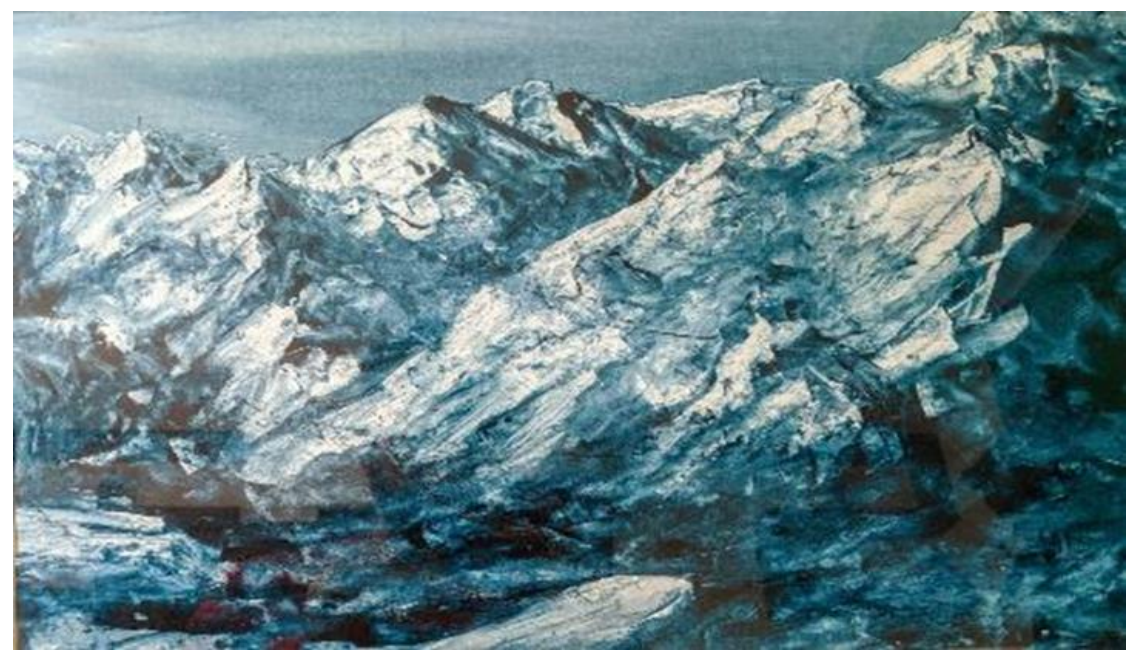

Figure 1: Kargil White Again-1999 by Rajendra Bhatia.

The concept of oil colours on paper is not new, rather it is conventional. It has been out there since 1700's (Lisa Marder, 2019). According to Winsor and Newton, despite of any rumours and of what people believe, it is perfectly possible to use oil on paper for sketching (Winsor and Newton, 2019). Professionals like it for its texture and drag. However, considering the compatibility of oil colours on paper, it is not traditional. Paper is an excellent flexible surface to paint with, when prepared properly. It is relatively cheaper compared to other supports such as linen, canvas, and artboards. It has advantages in terms of usability. It has been extensively used for small studies, fast sketching, on site paintings and as the support for medium-sized paintings (Lisa Marder, 2019).

John Constable (1776-1837) was the English Romantic Landscape painter, who made many paintings in oil on paper. In this context, Albert Museum stated that in early 1800s, many artists, including Constable pursued to capture the subtle effects of light and atmosphere as is evident in Brighton Beach oil painting made by John Constable (figure 2). They attempted to do so on a small-scale oil sketches byopen air, by by using colours in a variety of ways such as application of thickly applied paint (Impasto), translucent oil paint (glazes) and by heavy dots of bright colour with light touches of pure white. They incorporated transparency in layers through dry brush effect as evident in one of his painting (figure 2) from 1824. This was done by quick strokes with a brush bearing a small amount of paint, which allowed the underneath colour to show through (Lisa Marder, 2019).

Conventionally, oil colours are made by mixing and then subsequently pulverizing the powder with the drying oil. Most commonly linseed oil was in use (Smith 1987). Depending upon the pigment used, the quantity of oil varied to achieve the desired consistency (Gettens, Stout 1966). Additionally, oil binders were added to this homogenous mixture in order to impart transparency to the colour and a gloss, which served the scope for the artist. Oil colours give the freedom for glazing which is addition of layers on top of previous layer in order to achieve the desired result (Mayer 1991). The glazing and subsequent transparency can be seen in the work of van der Weyden, shown in the figure 3. 


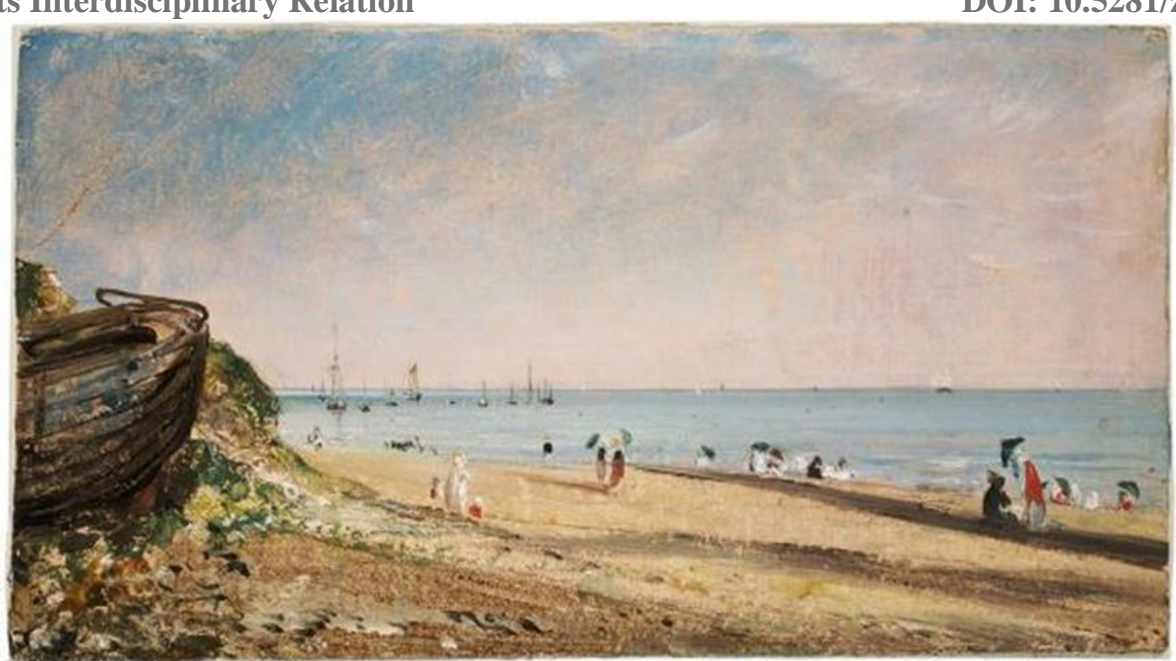

Figure 2: Brighton Beach, oil painting, John Constable, 1824, England. Museum no. 335-1888. (C) Victoria and Albert Museum, London. In this painting Constable first primed the handmade card with a coloured ground. These grounds were left visible at some places to give a particular atmosphere to the scenes. This can be seen with two scenes painted on Brighton Beach in 1824 . He used a pink ground for a sunny evening in July and a brown ground for a stormy day with dark clouds approaching.

In this painting Constable first primed the handmade card with a coloured ground. These grounds were left visible at some places to give a particular atmosphere to the scenes. This can be seen with two scenes painted on Brighton Beach in 1824. He used a pink ground for a sunny evening in July and a brown ground for a stormy day with dark clouds approaching.

There are many instances from the past where the artists used to paint directly on the paper support instead of the thin paper which after absorption of oil provided a damper surface for painting. This also allowed them to paint thin washes of oil colour for greater transparency without losing the hue and the intensity of the pigment (Mayer 1991).

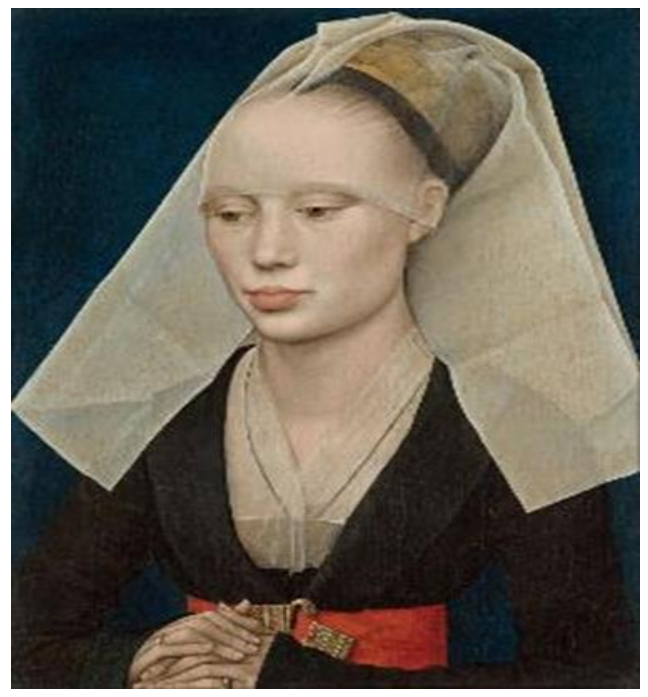

Figure 3: Shows the transparency in the layers revealing the underneath layers. 


\section{About Oil Colours}

The chief component of paint is the binder, which is generally a natural or synthetic resin, vegetable oils, natural proteins or fat (Mohie et al., 2019). These substances are responsible for the formation of film and adhesion of the paint to the various surfaces (Standeven 2013). The binders when mixed with the solvent systems such as oil, kerosene, turpentine, etc., are called as vehicle. The oil used in such paints do not evaporate like water but instead they polymerise into a dry semisolid. Their rate of drying depends on the degree of saturation in the oil used as a vehicle. Linseed oil is a highly polyunsaturated fat making it the most suitable and ideal vehicle for preparing oil colours (Standeven 2013).

The composition of the binder decides the basic properties of the paint such as drying, gloss, durability, flexibility, adhesion, scratch resistance, abrasion resistance, chemical resistance, etc (Dutta et al., 2009). The gloss in any oil paintings depends on two factors, amount of oil used in the vehicle and the thickness of the applied paint. Traditionally oil paintings were preferred over other paints because it retains the brightness in the colour and provides a glossy finish. However, when the same colours are mixed with other solvents, the oil is diluted, and the painting appears dull. This can be handled by applying a thin coat of clear varnish over the dried paint. This additional coat protects the painting from oxidation, degradation and imparts the glossiness to the artwork.

Varnishes are resins which contain organic polymers. They polymerise on exposure to air and sunlight forming a semisolid layer on top of the painting. Many artists have mixed varnish with the oil paint and such paints are known as enamel paints. Enamel are also alkyd resins which hardens on exposure to air. In the 20th century, some artists used commercially available enamel paints in art including Pablo Picasso, Hermann-Paul, Jackson Pollock and Sidney Nolan (Dredge et al., 2013). Nolan has made several paintings with enamel-based paints under the series 'The Trail'-1947. He used Ripolin, a commercial enamel-based paint (not intended for artwork) for his paintings (Haynes and Haynes 1998).

Among the existing binder systems (apart from enamel-based paints), a highly versatile polyester polyol-based polyurethane resins are dominating the market. They possess excellent corrosion resistance, abrasion resistance, scratch resistance, flexibility and chemical resistance. Polyurethanes have particularly found immense numbers of applications in high performance coatings for the automotive, appliance and wood industries (Dutta et al., 2009). Polyurethane is made of organic units joined by urethane molecule (Soto et al., 2014). They are capable of fast drying and formation of stable and durable film in just one or two coats. Polyurethane coating cure after evaporation of the solvent used in the vehicle. They also act as binders and hence, show very good adhesive property on various surfaces (Deobbie Gartner Neighbor 2014).

Oil binders have been extensively used on paper supports such as sketches, studies, drawings and paintings executed with oil colours as well black and white prints of text with oil-based inks. These oil binders appear to pose certain concerns regarding the absorption and diffusion of oil medium, discoloration and alteration of mechanical properties which might lead to embrittlement of the paper support. The degree of these effects might vary extensively based on the type of oil binder and the technique used in painting. The successive layering of oil colour (glazing) may, lead to the accumulation of oil binders on the paper support which might be responsible for the absorption of 
oil colours on the paper and the paper support (refer figure 5 back) and thus, justify the visible signs of mechanical degradation of the paper and the painting. Throughout history there are many such examples where oil colour on papers have led to severe distortion of the work due to noncompatibility of the paper support and the oil binder (Engram 1991) as evident in one of the painting shown in figure 4 by Vabbe (Woman in Landscape) (Mayer 1991).
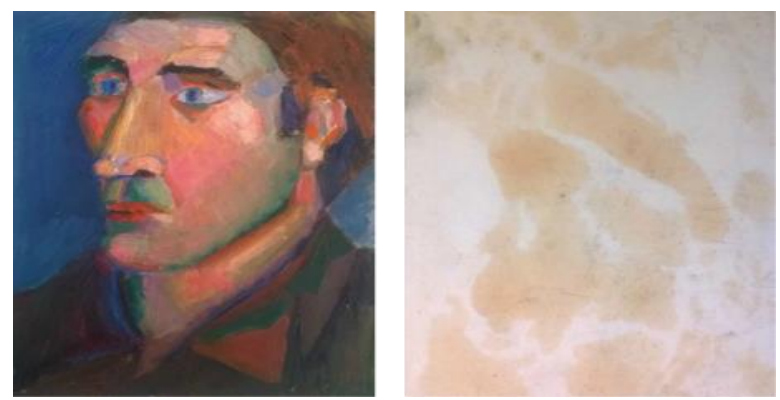

Figure 4: Stassinopoulos, Head of a man, oil on a light paper board (Recto and Verso). On the Verso, the paint covers the entire paper board, and on the Recto, discoloration due to absorption of oil binder is evident. Adopted from Banou et al., (2015)

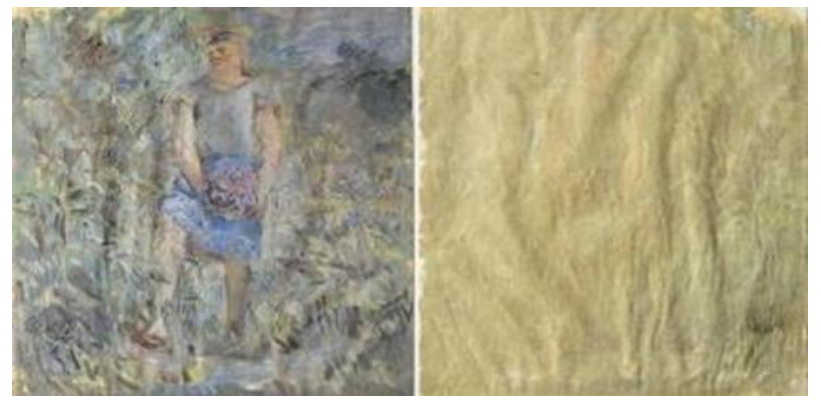

Figure 5: Woman in landscape by A. Vabbe (1936), front on the left and back on the right side of the reader is presented. The painting was made on non-grounded, primed, thin fragile paper $(0.9 \mathrm{~m}$ thick) with oil color. The paper is completely soaked in oil as seen in its back view and there is some shedding of paint and losses on the break lines. Adopted from Banou et al., (2015)

The risks of above-mentioned problems highly concern the conservators when they need to deal with the severe discoloration, absorption of oil and embrittlement caused to the paper support. This leads to the impression of local failure and crumbling; giving an idea that the support cannot hold the weight of the work (Engram 1991).

However, surveys and research work done on the paintings displayed in various museums around the world has offered ambiguous views (Kosek, Green 1992). These views are supported in the reference of oil works on manila envelope paper and handmade paper which are preserved in a great condition, even though both the papers are considered of inferior quality to cotton or linen rag papers used in that time (Banou et al. 2016).

\section{Pre-Treatment of Paper for Oil Paintings}

Considering the risks and the factors involved in oil painting on paper, people started to pre-treat the paper in order to make it suitable for oil painting. 
The art of pre-treatment of paper was known to man from the eighteenth century. Greek painters used to pre-coat the paper with animal glue, to seal the support, followed by the preparatory layer composed of the mixture of glue or oil and the pigments. Later they also used gesso for the ground layer on paper and then a layer of animal glue, to create a smooth, or sometimes coloured background for the succeeding painting. A final layer of varnish was coated on top of the painting for its protection (Banou et al., 2015).

In modern time there are various types of pre-treated papers available. The most common ones are the watercolor paper layered with primer. Watercolor paper is available in sheets as well as pads and blocks. Both pads and blocks are convenient and easy to prime. They are good for sketches, studies and plein art painting (Lisa Marder 2019). All these watercolor papers are handmade and cold pressed.

- Many different types of primed papers are available in the market such as Printing paper, Oil paper etc, which have an oil barrier that prevents absorption of water and solvents. In the same context some of the oil painting papers made by various manufacturers have been listed below.

- Oil painting papers: other manufacturers such as Beinfang, Bee Paper, Canson, Hahenmule, Royal and Langnickel and Strathmore also makes pre-treated oil papers which do not require any priming and are ready to use.

- Art Card Paper: It is a hot-pressed sheet, made of paper pulp. These sheets are technically referred as coated paper, as they are coated with a mixture of materials or a polymer, imparting certain qualities to the paper, including weight, surface gloss, smoothness or reduced ink absorbency. It comes in the range of 130 to $350 \mathrm{gsm}$. The author has used 300 gsm art card sheets for all the art works presented in this paper.

\section{Use of Oil Colour on Paper}

Oil colour on paper, in comparison to other types of work on art paper; such as watercolours and acrylic; is more complex, since the oil colours are heterogeneous laminar structures whose property depends more on the physical attributes of layering, viscoelastic properties of paper, support, size ground and the chemical composition of the paint and medium. These properties are subjective to change based on abiotic factors such as temperature, humidity and other environmental stress (Phenix 1995). In addition to this, the adhesion of the ground and the paint layer may diminish significantly resulting in mechanical damage to the paper (Banou, 2015).

After considering the approachability of oil colours on paper with respect to various binders and solvents, a technique was adopted from the past where oil colours were mixed with enamel as a binder and polyurethane, linseed oil and kerosene as solvents. Such a composition was named 'Oil on Paper School' (OOPS). The paper further discusses the techniques and methodologies that can be used with OOPS on cold, hard pressed art card paper of $300 \mathrm{gsm}$ to produce some amazing effects.

\section{Methodology}

OOPS comes in thick consistency which gives it an opaque colour by nature of its viscosity. However, opacity and transparency are achieved by adding appropriate amount of solvent to the colour for the desired effect. 
OOPS can be applied on paper as other conventio drawing surfaces with a similar process. This can be done by mixing OOPS and the solvent thoroughly to achieve a flowy consistency. This paint is then applied to the art card paper of 130 to 350 gsm or more, with the help of a flat wash brush. This is done in order to add background colour to the drawing surface.

The subjects of the painting are then painted using a thicker consistency OOPS colours. Dabbing of the brush and by adding solvent at times over the 'thickened' applied paint on paper, makes the paint to evenly coat the subject on the paper.

Transparency can be achieved by applying a thinner consistency of OOPS colour to the art card paper.

\section{Special effects using OOPS}

1) Formation of cells (bubbles) over the surface:

Conventionally, oil colours have not been used to create cells on the canvas or paper. They are generally created using silica-based flow mediums and acrylic colours. However, similar effects can be achieved by OOPS. In order to create the cells or bubble-like effect over the desired surface, linseed oil is applied with smooth strokes of brush over a semi-dried OOPS surface. This gives medium to large bubbles on the art work. A repeat of linseed oil application over these big bubbles/cells will lead to formation of smaller and increased number of bubbles/cells, imparting a look of rough texture. This technique results in beautiful and magical creations of bubbles in the art work as seen in the painting displayed in the figure 6. 'The Vase' by Rajendra Bhatia (2016).

2) Use of Palette knife:

A careful use of palette knife on OOPS can bring about transparency, a see-through effect and retain the opacity in different areas of the same surface. This technique has been used in the abovementioned painting (The Vase) in figure 6, in the detailing of the leaves. Another art work by the author, 'Kornish (back waters)' (2009) has been made using this technique as shown in the figure 7.

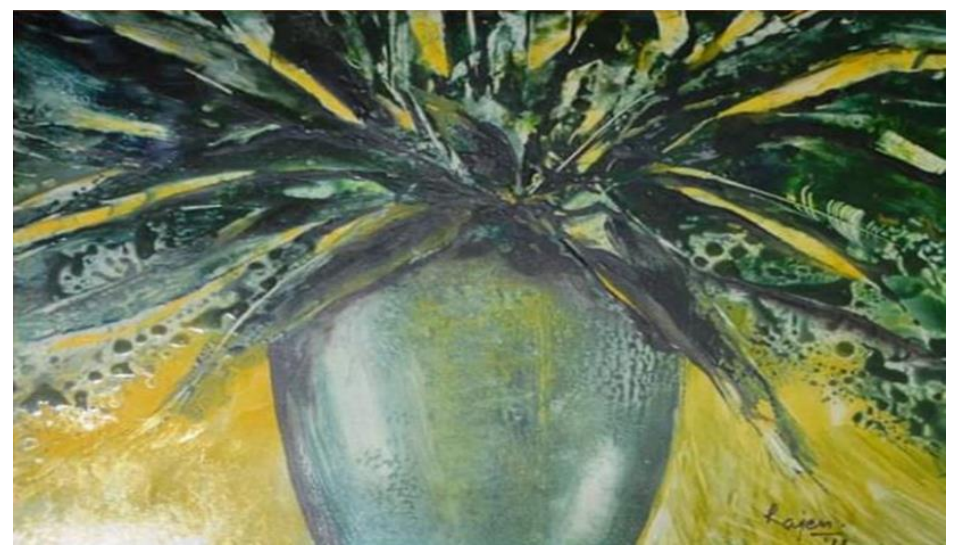

Figure 6: 'The Vase' by Rajendra Bhatia (2016). The painting illustrates the technique used for the formation of bubbles/cells, distinctly presented under the leaves and on the pre-painted background with acrylic colours, using repeated application of linseed oil. The leaves are made by using the edge of the palette knife, revealing the underneath yellow background. 


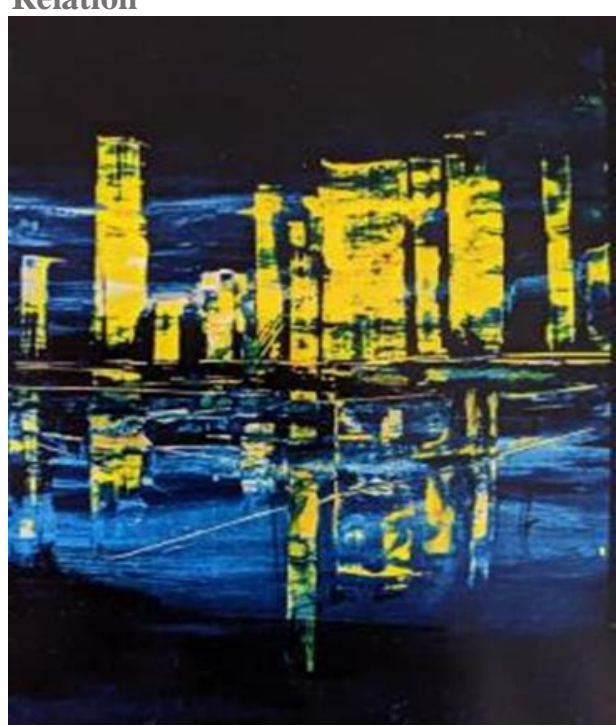

DOI: 10.5281/zenodo.3585043

Figure 7: Kornish (back waters) by Rajendra Bhatia (2009). The buildings and the reflection have been derived out of the background using a palette knife.

3) Use of cloth.

A clean cloth can be used to wipe off the already applied colour which is in process of drying, from different areas to reveal the down below surface. The use of knife and cloth is very useful in creation of negative-positive artworks as seen in another art work by the author in, 'White Flower'2006 (figure 8).

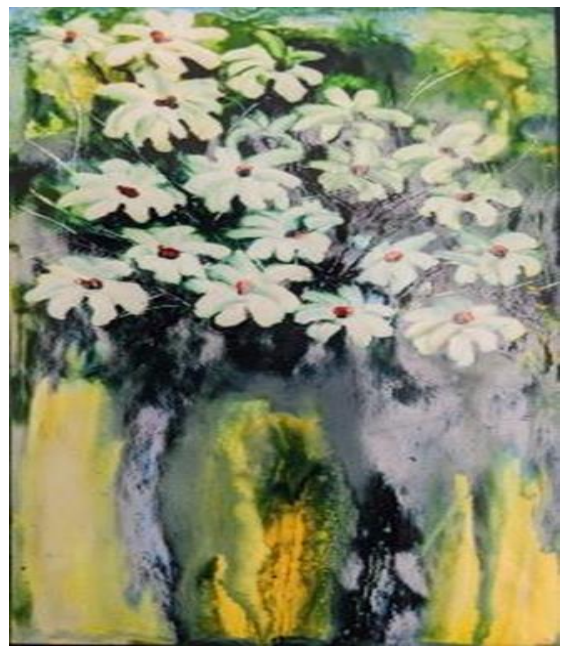

Figure 8: 'White Flower' by Rajendra Bhatia (2016). The individual petals in the white flowers are made using the technique of clean cloth in OOPS.

\section{4) Flow of Colours}

Like water colours can be flown on cold pressed hand-made sheets, OOPS can flow on the hotpressed sheet surfaces. This can be done by diluting the paint with solvent to a desired flowy consistency. After application of this paint to the paper, a mouth straw or a blower can be used to create beautiful, natural flow figures on the art work. Mixing linseed oil at times to the paint, gives 
a rough texture appearance to the flow figures. This technique has been used in the creation of another beautiful abstract painting by the author, shown in the figure 9 .

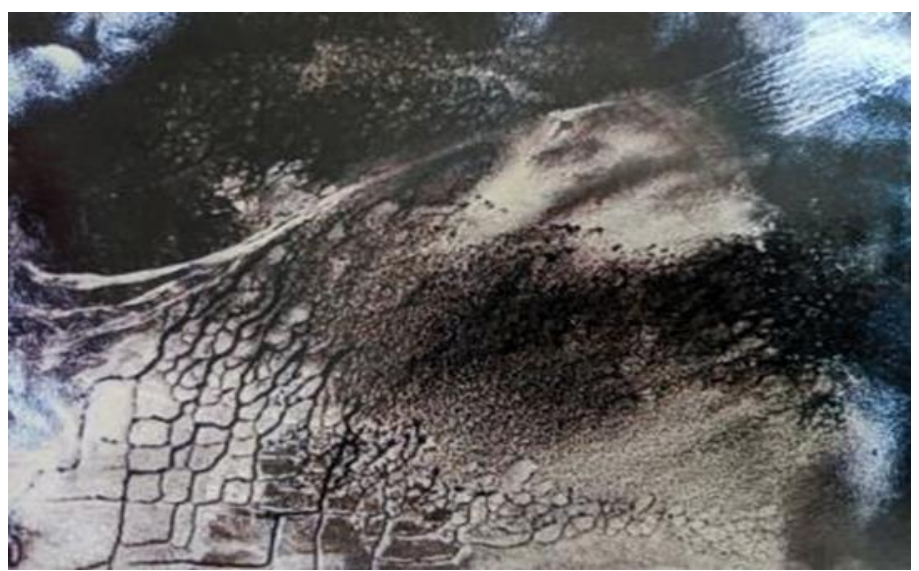

Figure 9: Abstract painting by Rajendra Bhatia (2012) displaying the flow of colours on the bottom left corner of the painting.

\section{5) Opaqueness with OOPS}

OOPS is opaque by the nature of its composition. This gives a bright luminance to the applied colour making the painting to pop out naturally. Figure 10 displays the opaqueness of OOPS, which was applied by fingers and brush.

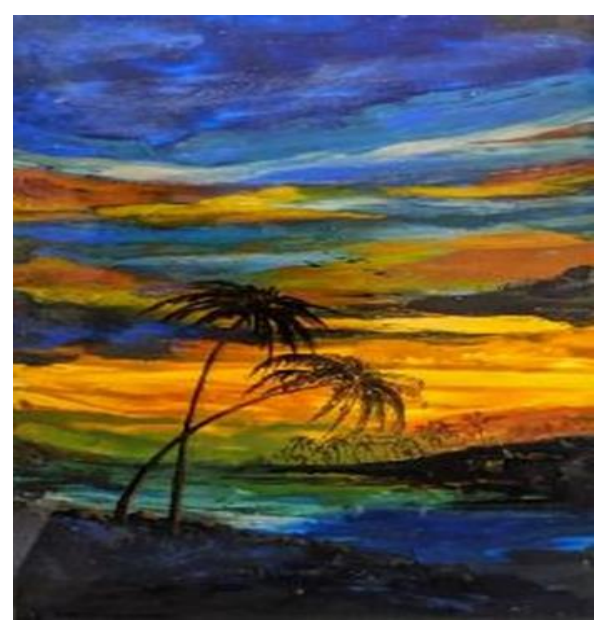

Figure 10: Memory of 'Kerala Kornish (2010) by Rajendra Bhatia. The painting displays the opaqueness of OOPS when applied thick and smudged with finger onto the art card paper.

6) Application of OOPS on a background which is already painted with acrylic colours A mystical effect can be created by applying a thin coat of OOPS on the pre-painted, hard dried acrylic background. Acrylic colours create a smooth surface while sealing off the pores in the paper. Hence, when OOPS is applied, there is a differential effect of the applied paint over acrylic base. Such an application of OOPS leave a very interesting impression over the acrylic base. The acrylic base has been used on several art work done by the author such as The Vase, Kornish: The Back Water, etc. 
7) Use of Sponge

The dabbing of sponge over the wet, semi-dried art work give some beautiful colour mixing, and mystical blending of the colour while working on the paper itself.

8) Use of Wedges

Sharp edged wedges are used with OOPS in various hand movements to add and scrape off colour at the same time, leaving a beautiful impression. This technique was used in creation of 'Ray of Hope' by the author as displayed in the figure 11.

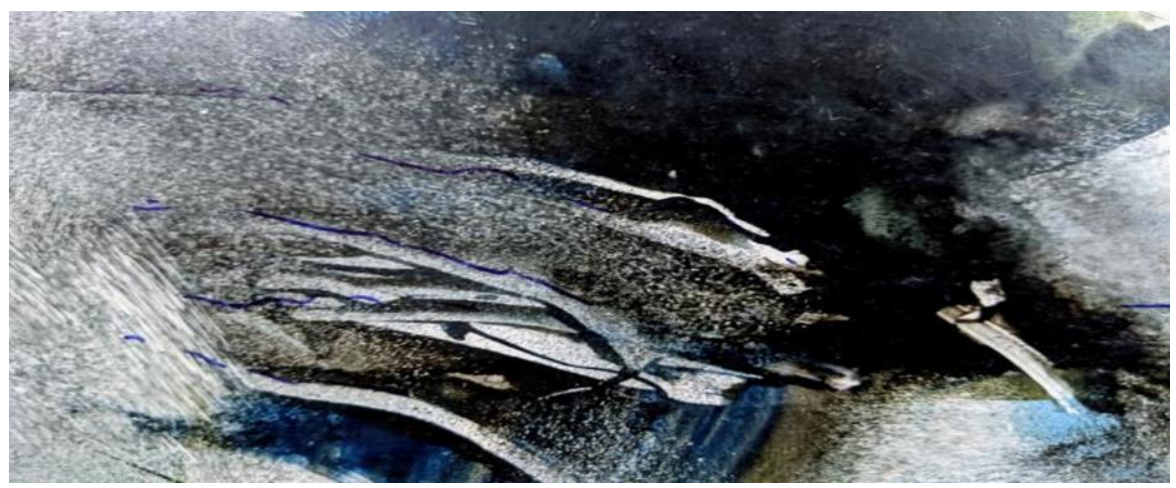

Figure 11: Ray of Hope by Rajendra Bhatia (2000). The figure shows a small portion from the actual painting where a wedge was used to produce this dramatic effect representing a ray of hope.

9) Use of Rubber Roller

Rollers are used for creation of background for abstract painting in acrylic medium. Similar or even better results can be achieved on paper by using rubber roller and sponge with OOPS.

\section{Discussion}

Addressing the question, whether OOPS is transparent or opaque.

OOPS comes in thick consistency, making it an opaque medium by nature of its composition and viscosity. However, opacity and transparency are relative terms. This can be explained with inflation of balloon. The balloon in its deflated form is completely opaque but as air is blown in, the balloon expands and the surface becomes translucent as evident from the figure 12 .

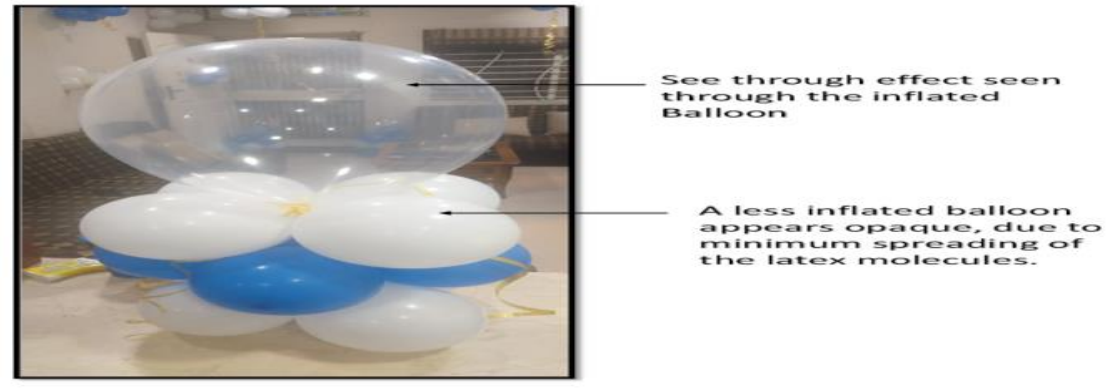

Figure 12: Representation of acquisition of transparency in the rubber due to spread of molecules in the balloon membrane on its inflation. This explains how OOPS imparts transparency to the opaque colour by the application of various techniques. 


\section{Demonstration of Transparency}

The rarefied pigment of OOPS make it translucent and an extra mix of clear, transparent turpentine provides almost a 'see through' kind of effect in the painted layer. The demonstration done on the black and white surfaces below (figure 13) show how transparency can be achieved through OOPS.

The colour when applied on the blackened strips, act as a control, demonstrating transparency where-as, when applied on the white sheet, the white of the sheet works as 'positive-negative' with respect to the master transparent medium. This has been further explained diagrammatically in figure 14

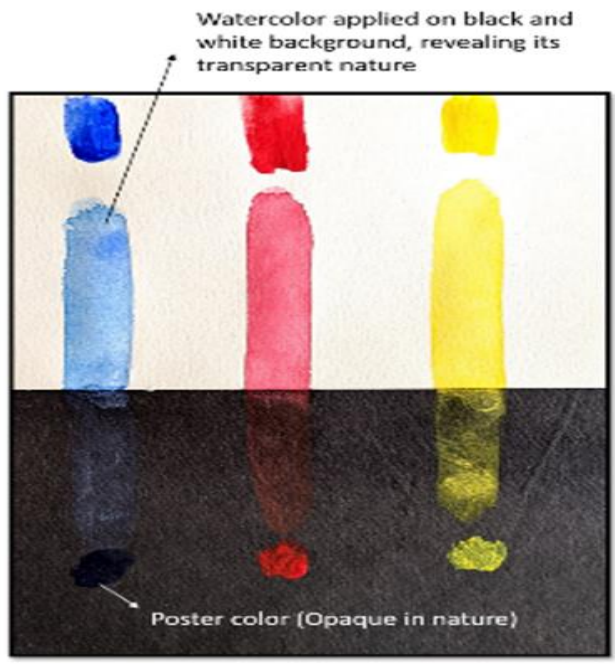

Water Color Paper

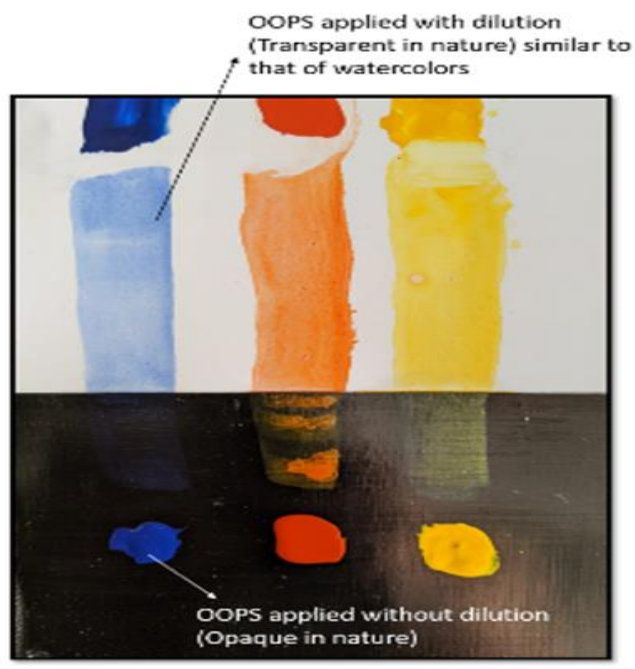

Art Card Paper

Figure 13: Demonstration of Transparency and opaqueness of OOPS (diluted and non-diluted, with solvent) over a white and black background (painted with acrylic) on art card sheet of 300 gsm, compared to the transparency of watercolours and opacity of poster colours when applied on black and white papers. The blackened surface acts as a control for displaying the transparency of the colour on white background.

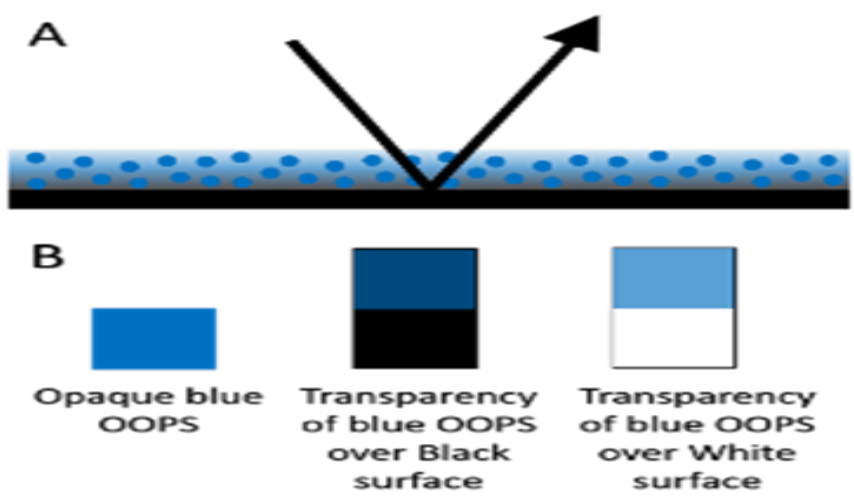

Figure 14: A) represents the rarefication of pigment molecules over the surface, providing transparency to the otherwise opaque colour. The light reflects from the OOPS layer as well as from the underneath background, thus providing a 'see through' effect to the applied colour. B) 
represents the change in the tint and shades of the opaque colour from dark to light based on the applied black and white surfaces respectively.

\section{A comparison of OOPS with water colours:}

OOPS when compared to water-colours, brings forth some interesting features.

- OOPS is simpler to handle, with much richer and complex results.

- OOPS is a forgiving colour. It can be erased from the mistake areas and the surface can be repainted. It is this feature of OOPS that has inspired the author to create the white flower painting (figure 8).

- Contrary to water colours, glazing with OOPS is complex. As the solvent (turpentine or kerosene) may dissolve the pigment from the underneath dried up layer and hence results in washing off the previous layer or the two colours get mixed up. However, a thin coat of polyurethane-color mixture can make glazing possible to a certain extent because polyurethane on drying creates a protective layer of over the adsorbed pigment layer, thereby preventing it from being dissolved by the solvent in the second layer of the paint.

- The prior application of acrylic colour as a base before applying OOPS and thereafter pulling/ scraping off some part of the colour brings about amazing effects with OOPS. Refer Kornish painting displayed in figure 7 by the author.

- Thick and thin OOPS application in a single layer is used to get opacity and transparency, which is explained by figure 13 .

- It is always safe to work with one or two layers of OOPS compared to many layers, which makes the colour opaque and muddy. The solvent of wet OOPS reacts with partially dried up painted surface.

- Most of OOPS; when applied on hot pressed art card, remains on the surface of the paper unlike water colours which go deep into the handmade, cold pressed sheets. The process of adhering to the surfaces that of OOPS and watercolours can be understood as adsorbing and absorbing.

- Thick and thin OOPS application in a single layer is used to get opacity and transparency, which is explained in with figure 15.

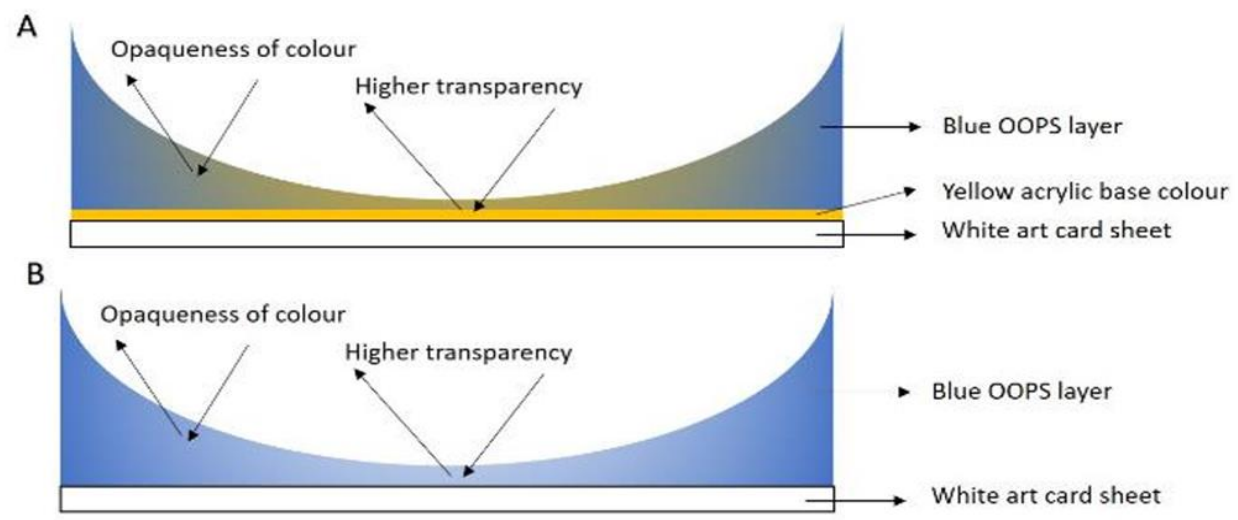

Figure 15: Diagrammatic representation of opacity and transparency in a single layer of OOPS application. When the applied wet color is scraped off gradually then a thin layer is formed which lets the light to pass through and reflect from the already coloured background. The diagram represents the phenomenon at a microscopic level. 


\section{The brightness of OOPS:}

The brightness of the OOPS is comparable to that of Impasto work. The thick layered colour in impasto paintings, appear bright because of the availability of high hue of the pigments on the surface of the thickly applied paint. In OOPS, the brightness and the hue are not affected because the pigments are not absorbed but rather adsorbed on the paper surface, hence a thin coat of colour also gives same shine, and brightness to that of an impasto work. Such a comparison of luminance can be seen in the figure 16, where a painting made with OOPS (Kornish) by the author is compared to Impasto work done by Monet (Water Lily).
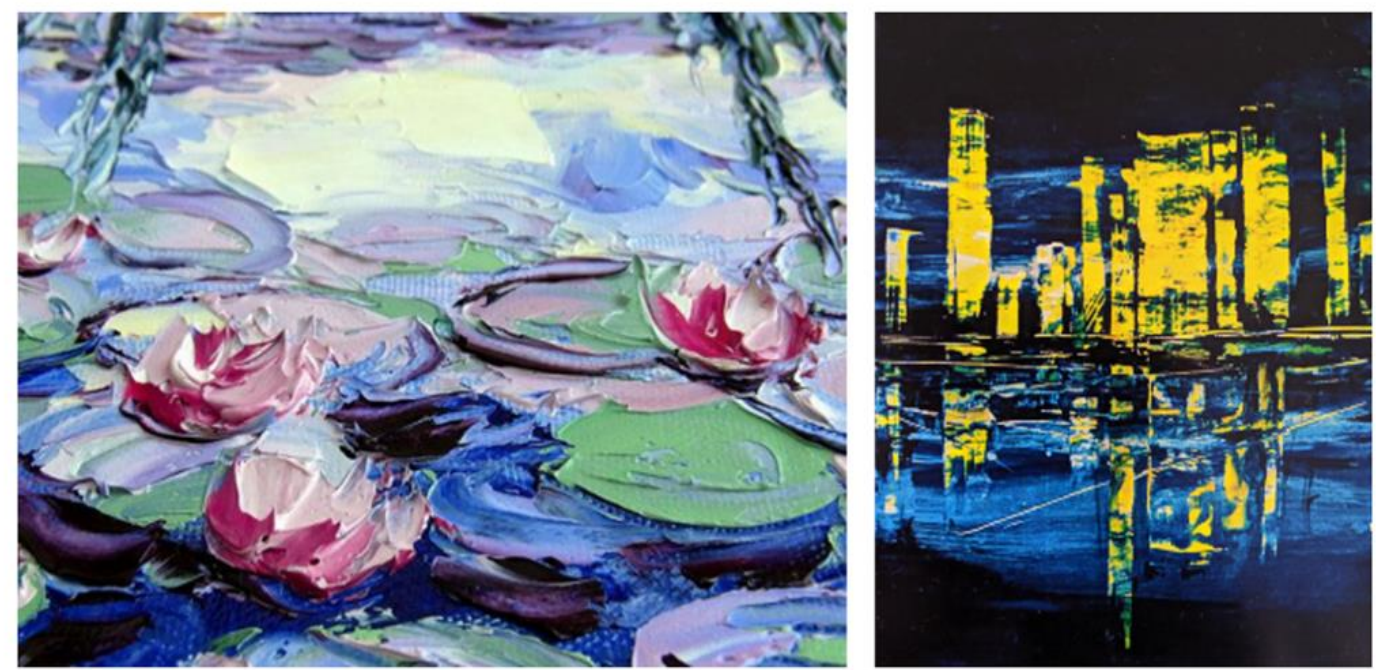

Figure 16: A) 'Water Lily'-1919 an Impasto work by Monet is compared with (B) the 'Kornish' made using OOPS by Rajendra Bhatia is compared for the luminance and the hue of the pigments.

\section{Preservation}

It is observed that paintings made on card sheets done by OOPS are well preserved compared to other paintings done on paper and canvas with water colour and oil medium respectively. The reasons for this preservation as per the author are:

- Enamel or polyurethane based colours do not seep through paper because of their high molecular size. Also, these mediums dry up before they can be absorbed by the pores of the paper. Hence, the oil in the colour is simply adsorbed by the paper. When the paper is not mounted on any support, the paper can breathe. Thus, creating an oxygen rich, dry atmosphere around the painting, preventing the growth of any anaerobic microorganisms.

- Paper is hygroscopic in nature; it curls and stretches in humid environment/ Hence, there are chances of damage to the art work in rainy seasons. This can be prevented by mounting the art card paper (used in to paint with OOPS) onto a self-adhering board. This board is coated with a resin which does not dry and hence the art work can be removed from the board at any time without losing the integrity of the art card. The resin seals off the pores from the bottom thereby, preventing absorption of water by the paper. 


\section{Author's Perspective over 'Kargil White Again'-1999}

\section{Contextual analysis:}

During May 1999 to July 1999, the Kargil war was fought between large troops of India and Pakistan, resulting in a 50-day war with more than 1200 causalities from India and Pakistan alltogether.

While the war was still being fought, the author painted this painting in the spirit of bringing peace. This painting is the representation of the cold, frigid summer-high mountains in the Kargil where the war was fought.

The paintings were named 'Kargil White Again'. The very name given to the series of paintings forecast purpose of its making. It also indicates the destruction caused to the nature and all the lives within and the core emotion that it carried. Here, 'Again' symbolises the timeline which moves from the past to the present. It gives the viewer an idea that something has been restored to its originality, its initial pride and luminosity. Here 'White' signifies serenity and peace which were lost during the war due to the blood shed over the white, snowy mountains.

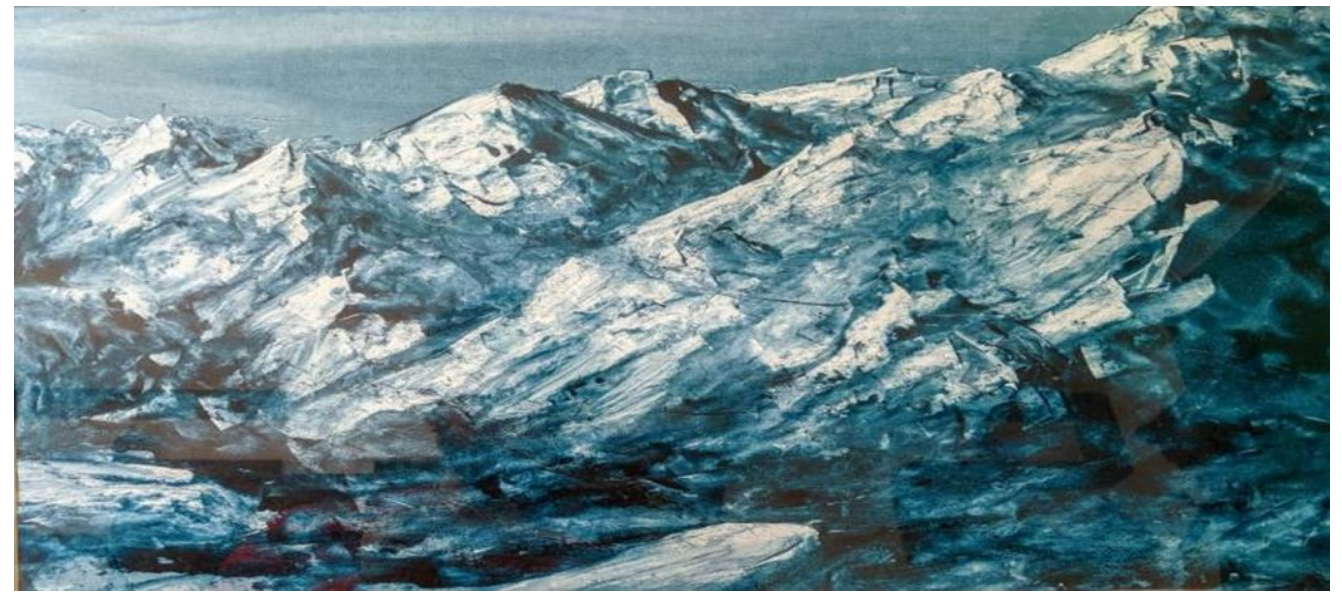

‘Kargil White Again'-1999 Painted by Rajendra Bhatia.

\section{Formal analysis:}

Scale:

The painting is of 23' 'x14', made on art card sheet of 300 gsm with OOPS colours.

\section{Composition:}

The painting is composed of two main elements, the sky and the voluminous mountains. A clear transparent sky can be seen on the top, which is contrasted by the light and dark blue mountains, underneath the sky, covering almost $85 \%$ of the painting.

\section{Pictorial Space:}

The source of light in this painting seems to be from the top left corner as shown in the figure 17. The light seems to illuminate only the topmost mountains while keeping the bottom one's dark. Thus, showing the illusory space in the painting. The dark mountains at the bottom are nearer to the observer, while the illuminated ones are far behind, giving a sense of depth to the two- 
dimensional painting. The painting displays the vastness and the stretch of the mountain range which extends beyond the observer's vision.

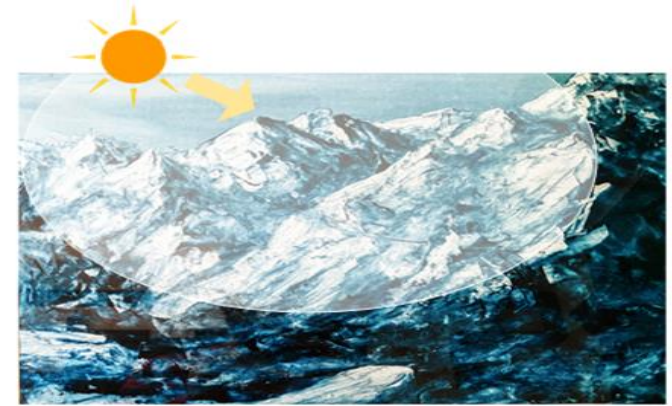

Figure 17: Source of light is from the top left corner illuminating the mountains.

\section{Form:}

The Painting has some sort of geometry in play. All the mountains are triangular and their edges seems to be corresponding to one another. When the diagonals are drawn across the painting, the edges of the mountains seem to be parallel to the diagonals, even at the bottom of the line of station, where the viewer is standing. As shown in the figure 18. The topmost central mountains also align within the red lines joining the midpoints of the edges of the painting. Thus, the geometric arrangement of mountains, gives a sense of fullness and volume to the painting.

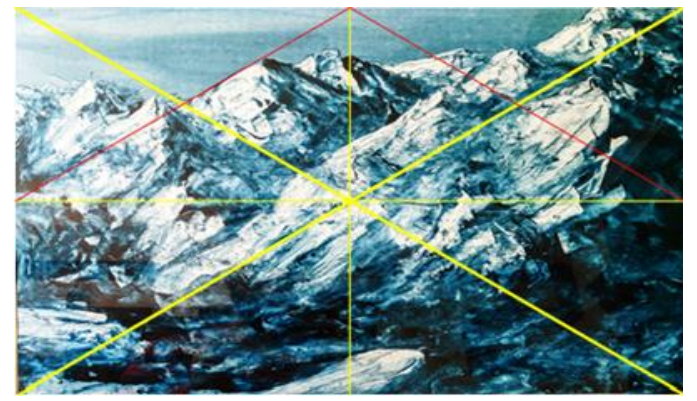

Figure 18: Analysis of the forms in the painting

\section{Lines:}

Lines are very important when it comes to distinguishing light and dark portions. In this painting, dark lines have been used to demarcate the peak of the mountains from the bright, soft sky (shown by red lines in the figure 19) and hence, reveal the sharp edges of the mountains.

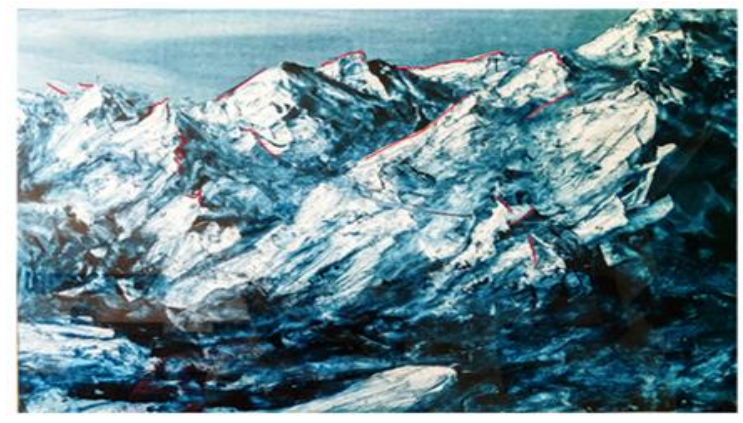

Figure 19: demarcation of lines in the painting with red marks 


\section{Colour:}

The painting is monochromatic with amazing variation in tint and shades with respect to transparency, translucency and opacity. A Cool colour (blue) has been used to give a sense of low temperature to the scene. The dark and light shades of the colour, without any addition of black or white to the paint brings about the bright hue of the colour in the darkest and the brightest areas in the painting. Such that, an opaque colour is used to bring about transparency, translucency and opaqueness in different areas of the painting by the application of various techniques.

\section{Texture:}

Sky is painted with a smooth texture, which gives a sense of calmness to the scene, while the mountains have a blunt texture, with sharp edges and contrasting colours, giving a sense of steep slopes. The bottom area has a rough texture, which gives an idea of uneven surface.

\section{Perspective:}

The painting brings about perspective with sense of foreshortening. The nearer mountain looks large while the rear mountain peaks look small. The mountain peaks at distance are not diminishing, showing a clear understanding that the air is rarefied and the in between atmosphere has no suspended particles.

\section{Composition:}

The painting has a Zig-Zag pyramidal composition with an acentric focus, which meet the requirement of law of third (Figure 20).
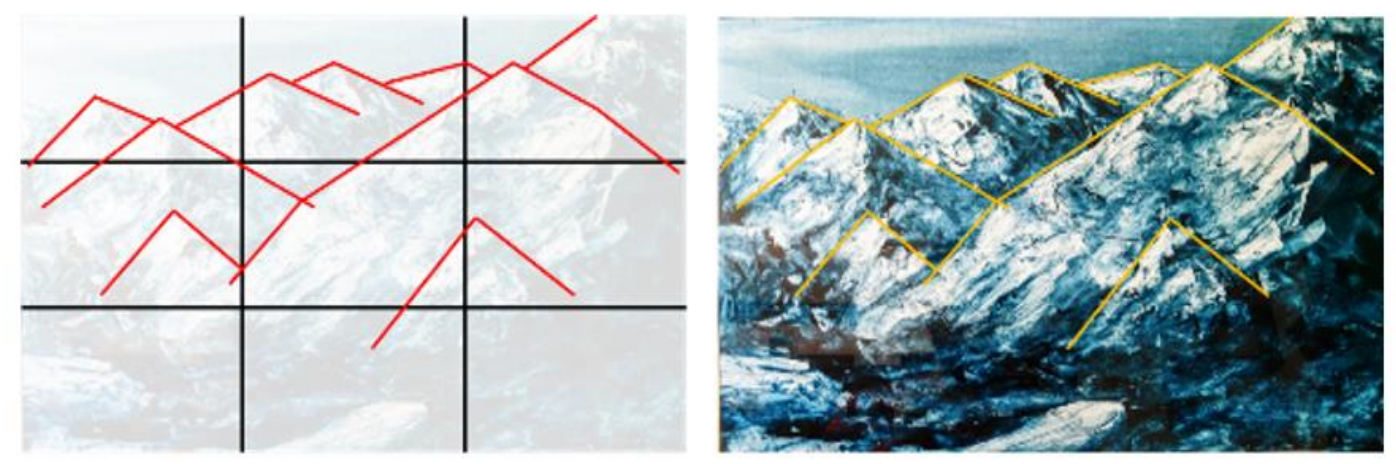

Figure 20: A Zig-Zag pyramidal composition with an acentric focus seen in the forms of mountains.

\section{Conclusion}

Oil colours have been extensively used from the past for they allow artists to make changes while the colour is still wet and allows them to mix the colours on the drawing surface. Oil paintings also produce bright hues after drying because of the formation of semi-dried oil layer over the adsorbed pigment. These characteristics have been exploited by artists in creation of fresco, impasto and oil paintings on paper.

Non pre-treated paper is not compatible for oil painting. However, they still have been used for making oil paintings. They need to be grounded, primed or coated with other mediums in order to prevent paper from soaking up the oil. Years of practices has led to the development of techniques, 
materials, and tools such as pre-treated water colour papers for creation of oil paintings on paper without any concerns. However, achieving transparency among opaque oil colours is still a less explored territory

Use of OOPS provide a technique, which is one of its kind. It uses enamel-based or polyurethanebased oil colour pigment with other solvents such as turpentine and kerosene to create some extraordinary effects on art card sheets. The unique techniques have been discussed with respect to various art works created on art card sheets using OOPS by the author. The paper also unfolds the story, the inspiration and the author's perspective over his first creation using OOPS, 'Kargil White Again'-1999 (figure 1).

\section{Acknowledgment}

First and foremost, I want to thank my mother Late Shiv Mohini Bhatia, who brought me to this world and gave me this instinct to do artworks and a thoughtfulness to analyse it. At times I feel that it is she who does it and I am just a channel.

I sincerely want to thank Dr. Kumkum Bharadwaj, HOD (D\&P), Maharani Laxmi bai Govt. Girls PG Girls college, Kila Maidan, Indore, to motivate and encourage me in writing this paper.

I also want to thank my friend Mr. Mufaddal Manaquib to support and help me in writing this paper.

\section{References}

[1] Mohie, M.A., Ali, N.M., Issa, B. and Alkareem, A.A., 2019. A NEW METHOD OF LINING OIL PAINTINGS USING POLYURETHANE. Mediterranean Archaeology \& Archaeometry, 19(2).

[2] Standeven, H.A., 2013. Oil-Based House Paints from 1900 to 1960: An Examination of Their History and Development, with Particular Reference to Ripolin Enamels. Journal of the American Institute for Conservation, 52(3), pp.127-139.

[3] Soto, M., Sebastian, R.M. and Marquet, J., 2014. Photochemical activation of extremely weak nucleophiles: highly fluorinated urethanes and polyurethanes from polyfluoro alcohols. The Journal of organic chemistry, 79(11), pp.5019-5027.

[4] Haynes, R.D. and Haynes, R.D., 1998. Seeking the centre: The Australian desert in literature, art and film. Cambridge University Press.

[5] Dredge, P., Schilling, M.R., Gautier, G., Mazurek, J., Learner, T. and Wuhrer, R., 2013. Lifting the lids off Ripolin: a collection of paint from Sidney Nolan's studio. Journal of the American Institute for Conservation, 52(4), pp.213-226.

[6] Dutta, S., Karak, N. and Jana, T., 2009. Evaluation of Mesua ferrea L. seed oil modified polyurethane paints. Progress in Organic Coatings, 65(1), pp.131-135.

[7] Winson and Newton (2019) Available at: http://www.winsornewton.com/na/discover/tips-andtechniques (Accessed 22/10/2019)

[8] Penelope Banou, Athena Alexopoulou \& Brian W. Singer (2015) The Treatment of Oil Paintings on Paper Supports Considerations on the Treatment Applications Used from the Past until the Present, Journal of Paper Conservation, 16:1, 29-36

[9] Banou, Penelope \& Singer, Brian \& Alexopoulou, Athena. (2016). Investigating the Effect of Oil Medium on the Paper Supports of Works of Art. A Discussion on Factors, Mechanisms and Effects involved. ERC Newsletter 1/2016. 
[10] Lisa Marder (2019) Available at: https://www.thesprucecrafts.com/painting-on-paper-with-oils2578730 (Accessed on 24/10/2019)

[11] Kosek, J. and Green, L.R., 1992. A survey of oil paintings and sketches on paper in the collection in the British Museum: an assessment of stability. In The Institute of Paper Conservation: conference papers Manchester 1992 (pp. 96-102).

[12] Engram, C., 1991. Oil painting on paper and board supports. AICCM Bulletin, 17(3-4), pp.13-21.

[13] Banou, Penelope; Alexopoulou, Athena; Chranioti, Chraikleia; Tsimogiannis, Dimitris; Terlixi, Agni-Vasilia; Zervos, Spyros; Singer, Brian W. 2014. Oil based on paper. Investigating the effect of oil medium on the paper supports via VOC emission analysis. In: 11th International Conference on Non-Destructive Investigations and Microanalysis for the Diagnostics and Conservation of Cultural and Environmental Heritage, 11-13 of June 2014, Madrid, Spain - Contribution ID33 in the full paper CD.

[14] Deobbie Gartner Neighbor (2014). Available at: https://patch.com/new-york/larchmont/how-longdoes-it-take-polyurethane-to-dry-on-the-floors (Accessed on 24/10/2019)

[15] Gettens, R.J. and Stout, G.L., 1966. Painting materials: a short encyclopaedia. Courier Corporation.

[16] Phenix, A., 1995. The lining of paintings: traditions, principles and developments. In Lining and backing: the support of paintings, paper and textiles. Papers delivered at the UKIC conference, 78 November 1995 (pp. 21-33).

[17] Smith, Ray 1987. The artist's handbook, London. p-127 Mayer, Ralph 1991. The artist's handbook of materials and techniques, 5th edition revised and expanded by Steven Sheehan, New York. P$175 b$ 